\title{
Design and Implementation of a Smart Surveillance System
}

\author{
Oluwaseun Olujide Ilori \\ Department of Electrical \\ Electronics and Computer \\ University of Uyo
}

\author{
Kingsley Monday Udofia \\ Department of Electrical \\ Electronics and Computer \\ University of Uyo
}

\author{
Unwana Ubong Iwok \\ Department of Electrical \\ Electronics and Computer \\ University of Uyo
}

\begin{abstract}
In this paper, a smart surveillance system for home security is developed. The system consists of a motion detection system, an authentication system, an alert system and a web application control panel. It uses raspberry pi as the main controller which was programmed using python, a PIR sensor and a camera for motion detection and taking of images, an RFID reader/card for authentication, a USB modem for phone calls which also connect the device to the internet to allow it send images of an intruder to the owners email, a buzzer as an alarm and a web application control panel that could be accessed over the raspberry pi's Wi-Fi to manage the system. This system was tested using various scenarios such as user authentication, intruder or wrong authentication and it worked as expected.
\end{abstract}

\section{General Terms}

Security.

\section{Keywords}

Closed-Circuit Television, Surveillance, Raspberry pi, Motion Detection, RFID Authentication.

\section{INTRODUCTION}

Video surveillance systems popularly known as Closed-circuit television (CCTV) have been around since the 20th Century. One of the first recorded applications for closed circuit television system (CCTV) was in 1942 when it was used to view the launch of V2 rockets in Germany [1]. Traditionally, the system consists of cameras attached to monitor screens. CCTV systems are installed to give an overview of a large area to a limited number of operators [2].

In times past, security personnel will have to constantly watch multiple screens in a room all day in order to detect intrusion or review hours of stored footage of intrusion that took place when the security personnel was unavailable [3]. With advancements in technology, many improvements have been made to video surveillance systems making them smarter.

Today, video surveillance systems have found their applications in various sectors in our society. These devices have been a key component in ensuring security at airports, banks, prisons, schools, residential areas, to mention a few [4]. Criminal activities are becoming very dexterous nowadays, through intelligent and novel methods criminals are manoeuvring to succeed in their activities in residential apartments. The need for safety of life and property cannot be over emphasised and with the rising costs of security installations, a cost effective alternative is always a welcomed option [5].
The raspberry pi is a cheap and effective microcomputer that is able to meet the needs for home surveillance systems because it has the ability to be interfaced with other modules to develop automated systems. [3]. By integrating a passive infrared sensor (PIR), an RFID reader/card, a USB camera and a USB modem with the raspberry pi, it is possible to achieve a simple smart home surveillance system that provides a suitable alternative to home surveillance for private home owners.

This work is focused on developing a smart surveillance system which will be used at the entrances of residential premises. This system incorporates a motion detection system, an authentication system using RFID technology, an alert system that would notify the owner of an intruder and a web application control panel to manage the system.

\section{REVIEW OF RELATED WORK}

Lee \& Chuah developed a smart indoor home surveillance monitoring system using raspberry pi, a PIR sensor and a webcam. Motion in the room triggered the PIR sensor which captured images of any intruder and using internet connectivity from a wireless network the images are sent to the owners Dropbox Cloud storage which was then followed by an email and an SMS notification. The system lacked intruder authentication which inadvertently made the owner appear as an intruder in his own premises. The PIR seneor was the only means of intruder detection which made the system prone to false alerts, another flaw to the surveillance system.

A Motion Detector Security System for Indoor Geolocation was developed by (Nosiri et al) [5].This project focused on developing a security system used indoors at the entrances of homes. It has a motion detection module, video capturing module, SMS notification module and a web server module. The system was able to detect motion (intruder), activate the embedded camera to take frames of video after motion was sensed and store the video on a web server with an SMS alert to the notify the owner. This system did not also have an authentication module meaning the owner could be seen as an intruder and in the absence of internet connectivity, the owner would not be alerted since the SMS notification module uses internet.

Access Control of Door and Home Security by Raspberry Pi through Internet was developed by (Nasimuzzaman et al) [7].This made use of a PIR sensor, an LCD, Wi-Fi camera, raspberry pi and a Wi-Fi dongle. When the PIR sensor detects motion, the Wi-Fi camera is activated to take a photo and email the attachment to the respective email and at the same time generate a tweet to notify the administrator about the visitor with pictures. The administrator could see the visitor 
and notify the visitor via tweets and the visitor can view on the screen or he can send a command via twitter to unlock the door. The owner has no way of verifying himself, so when he gets to his door an image of him is also taken and if there is power failure, he would not have access to his apartment because of the magnetic lock

Live Streaming Motion Detection Camera Security System with Email Notification using Raspberry Pi was developed by (Angela \& Gidveer) [8]. This security system made use of raspberry pi as the main controller, a PIR sensor and a webcam for motion. The PIR sensor and the camera detect motion, sound an alarm, save the images and send them to the owner's email. The LAN connection enables the raspberry pi to connect to the internet. It also makes use of an android application to activate and deactivate the system. Using LAN connection for internet access requires an external peripheral like a router or another computer with internet connectivity.

The above systems present cost-effective alternatives to home surveillance with their main drawbacks centred on no satisfactory or non-existing authentication and cumbersome internet access. This work seeks to address some of these issues.

\section{METHODOLOGY}

The smart surveillance system is designed to detect the presence of an individual entering a room. When motion is detected by both the PIR sensor and the camera, images are taken and saved. The design offers two authentication windows. The first window of authentication is an initial period of 8 seconds from the moment human presence has been detected and confirmed by both the PIR sensor and the camera. When these 8 seconds elapse and no authentication via an RFID card has been recorded another window is given for final authentication of visitor (intruder). This final window is a 15 second period in which if an authentication is still not recorded from the visitor, the instant the period elapses the system notifies the owner via email containing photos of the intruder. The raspberry pi used in the design of the system is connected to the internet using a USB modem which also doubles for use in placing a phone call to the owner of the surveillance system. The control panel running on the device can be accessed over Wi-Fi using any internet browser where the owner can start the surveillance system, shut it down, reboot and manage saved photos. This system provides realtime surveillance and photos to the owner thereby giving ample time to the owner to take any necessary action as he may see fit Figure 1 shows the block diagram of the proposed system.

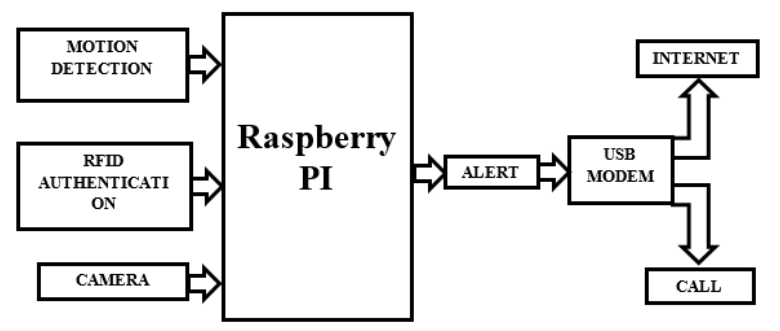

Figure 1: Block diagram of system

The motion detection system consists of a PIR sensor and a USB camera which are always active. While the PIR sensor checks for the presence of a human in the room, the camera checks for the changes in the background in the room. The system is designed in a manner that synchronizes the output of the PIR sensor and the output of the camera. When the PIR sensor detects intrusion and the camera senses changes in the background the two outputs simultaneously trigger photos to be taken every second. This method reduces chances of false alerts in the system. The flowchart of the motion detection system is as shown in figure 2 .

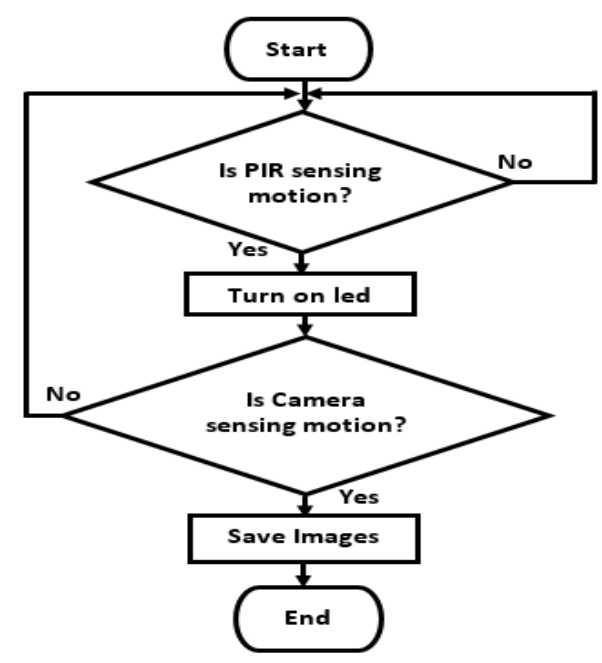

Figure 2: Flow chart of motion detection system

For the RFID authentication, an RFID reader is used to check the unique id of the card or tag presented for authentication. If the correct card is authenticated within eight (8) seconds, the system is deactivated but if the wrong or no card is read within 8 seconds, it sounds the alarm and copies images to the server. It then gives 15 seconds to verify with the right tag after which if the right card is not authenticated it alerts the owner. The RFID authentication flowchart is shown in figure 3.

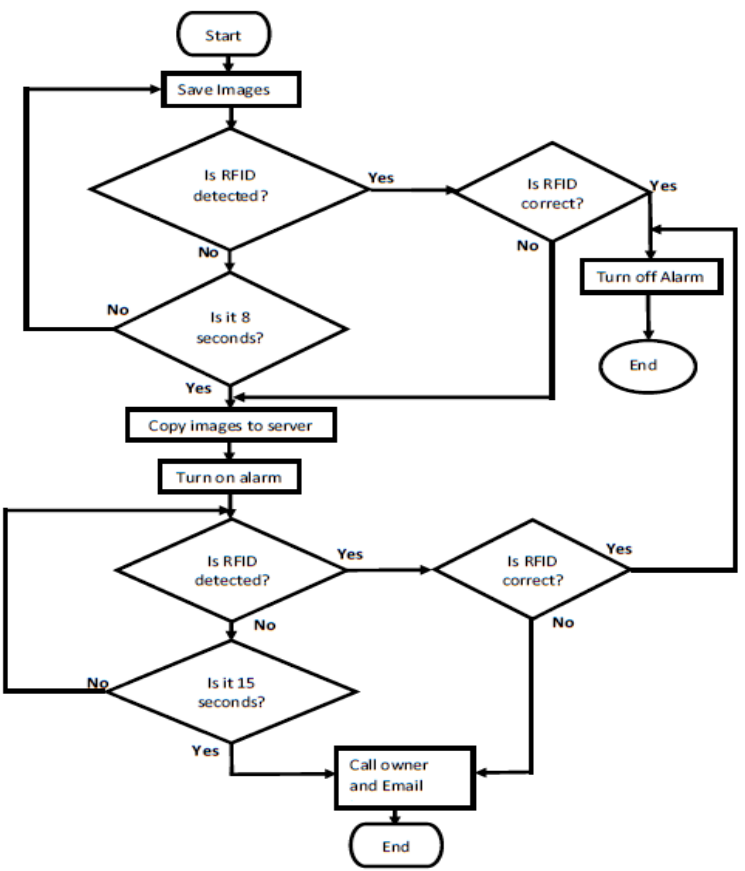

Figure 3: Flow chart of authentication system 
For the alert system, this unit is activated after the 8 seconds interval and the alarm turns on reminding the user to verify with the correct RFID card. If the right RFID tag is detected within the second window of 15 seconds the system is deactivated but if the wrong or no tag is presented within the second window of 15 seconds then the system calls the owner. If there is internet connectivity it sends photos via email but if there is none it keeps on trying to send until there is connectivity. A utility called "WvDial" was installed on the raspberry pi to enable it use the modem connect to the internet. See figure 4 for alert system flowchart.

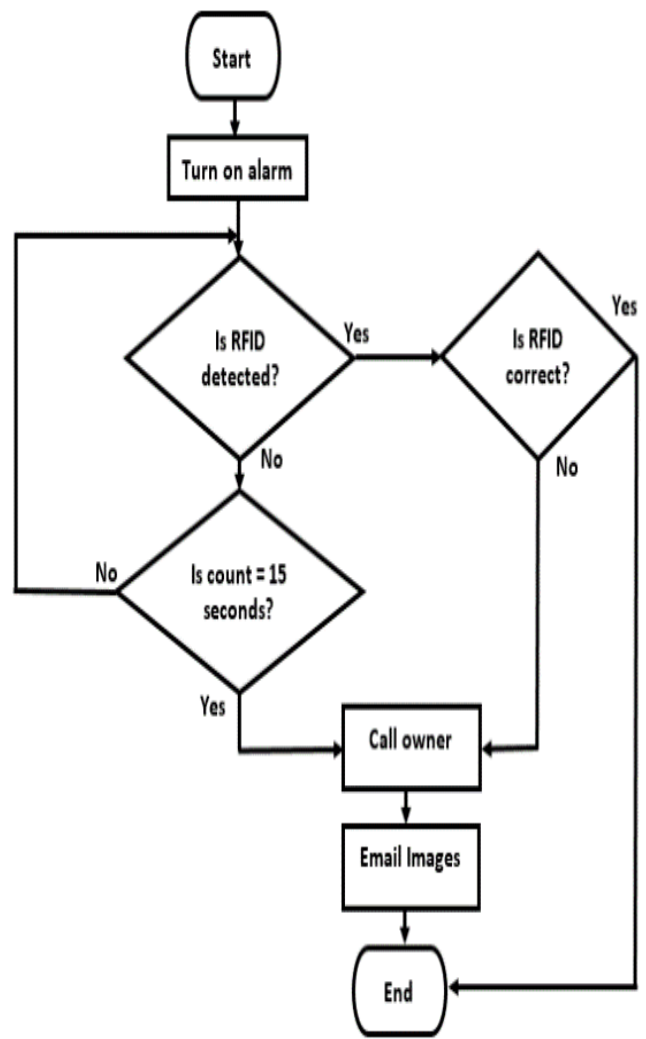

Figure 4: Flow chart of Phone call and Email Alert System

The web control panel could be accessed through an internet browser on the owner's phone via wireless local area network created by the raspberry pi with a web server being run on it. Once connected, the user can access the web application control panel by using the IP address and port of the web server. The control panel allows the user to start the surveillance system, shutdown or reboot the system, and manage photos saved by allowing the user to view and delete photos taken. In order to access to the file manager, shutdown or reboot features the user must login. Below in figure 5 is the flowchart of the web application.

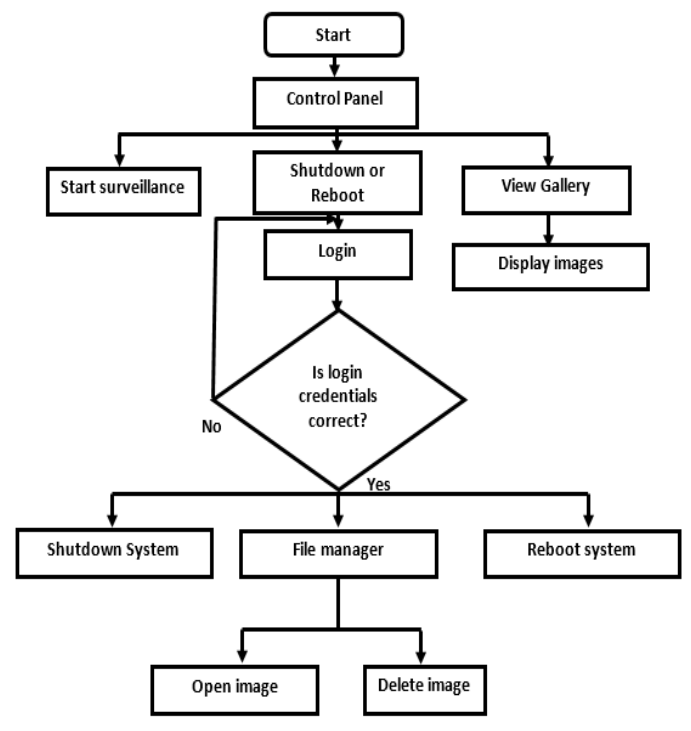

Figure 5: Flowchart of Web application control panel

\section{RESULTS}

The USB camera and the USB modem were plugged into the USB ports of the Raspberry pi while the PIR sensor, the RFID card reader, the buzzer and the Led were connected to the GPIO pins using jumper wires. See figure 6 .

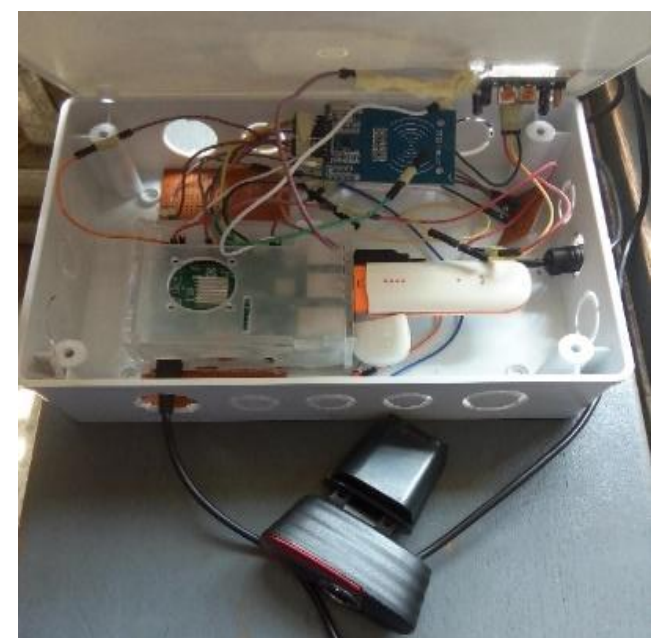

Figure 6: Internal view of prototype

All units represented in the web application worked as expected. Below is a screenshot of the web application interface which was accessed from an internet browser when connected to the wireless local area network created by the raspberry pi.

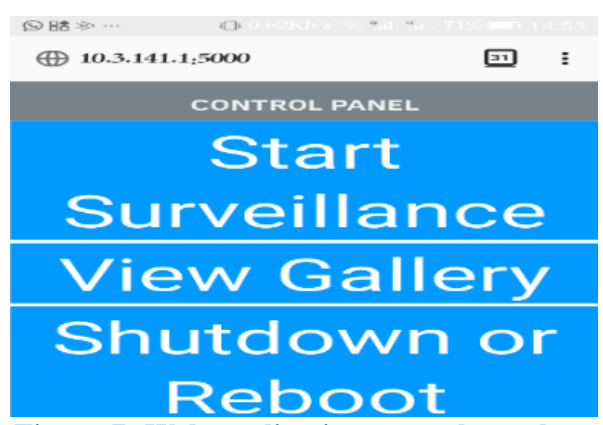

Figure 7: Web application control panel 
Table 1: Test results of different scenarios

\begin{tabular}{|c|c|c|c|c|c|}
\hline Actions & $\begin{array}{c}\text { Case } \\
1\end{array}$ & $\begin{array}{c}\text { Case } \\
2\end{array}$ & $\begin{array}{c}\text { Case } \\
3\end{array}$ & $\begin{array}{c}\text { Case } \\
4\end{array}$ & $\begin{array}{c}\text { Case } \\
5\end{array}$ \\
\hline $\begin{array}{l}\text { PIR detected } \\
\text { motion? }\end{array}$ & Yes & Yes & Yes & Yes & No \\
\hline $\begin{array}{l}\text { Camera } \\
\text { detected } \\
\text { motion? }\end{array}$ & Yes & Yes & Yes & No & Yes \\
\hline $\begin{array}{l}\text { Images } \\
\text { saved? }\end{array}$ & Yes & Yes & Yes & No & No \\
\hline $\begin{array}{c}\text { Right Card } \\
\text { verified } \\
\text { under } 8 \\
\text { seconds? }\end{array}$ & Yes & No & No & No & No \\
\hline Alarm? & No & Yes & Yes & No & No \\
\hline $\begin{array}{l}\text { Images } \\
\text { saved to } \\
\text { server? }\end{array}$ & No & Yes & Yes & No & No \\
\hline $\begin{array}{l}\text { Right card } \\
\text { verified } \\
\text { under } 15 \\
\text { seconds? }\end{array}$ & No & Yes & No & No & No \\
\hline $\begin{array}{c}\text { Was call } \\
\text { Received? }\end{array}$ & No & No & Yes & No & No \\
\hline $\begin{array}{c}\text { Were images } \\
\text { sent? }\end{array}$ & No & No & Yes & No & No \\
\hline
\end{tabular}

\subsection{User Authentication Scenarios}

\subsubsection{User Authentication - Case 1}

This represents a scenario where an individual enters the room and verifies using the correct RFID card before the alarm goes off. This is shown in figure 8 below.



Figure 8: User Authenticated before alarm

\subsubsection{User Authentication - Case 2}

This scenario occurs when an individual enters a room, forgets to perform authentication within 8 seconds, when the individual later verifies within the fifteen (15) second window, the system will be deactivated but pictures will be saved to the server to allow the owner see the individual who did not verify himself in time or if it was an intruder that verified using the right RFID card. This is shown in figure 9.

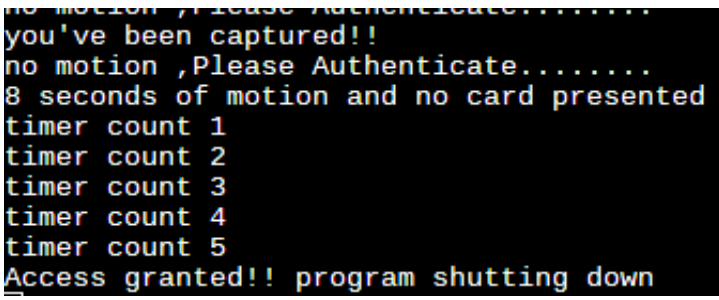

Figure 9: User Authenticated After alarm
4.1.3 Intruder/Wrong Authentication-Case 3

This occurs when an intruder breaks in and is seen by the both the camera and the infrared sensor. Since the intruder does not have an RFID card, or verifies using the wrong RFID card the alarm goes off, images are saved to the server and the owner of the house is alert via a phone call and email. See figure 10 and 11 .

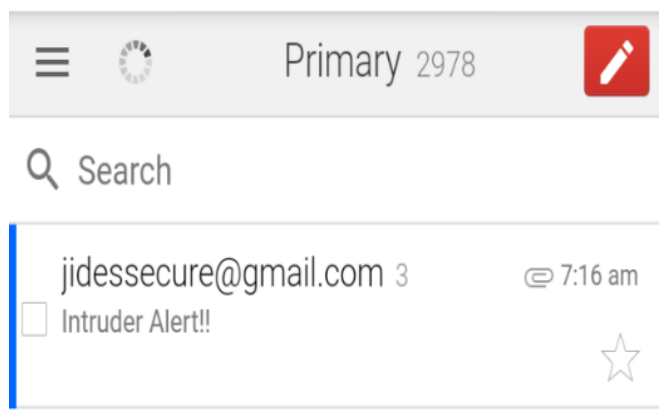

Figure 10: Email alert

Home Surveillance

K 09058529925 11-20 QRang 3 times

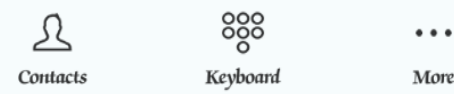

Figure 11: Phone call alert

\subsubsection{Poor Calibration-Case 4}

This could occur if the sensors were not calibrated properly. If only the PIR sensor detects motion, the system won't sound alarm, the camera would not take pictures and the system would not alert the owner.

\subsubsection{Poor Calibration-Case 5}

Here the camera only detected motion. The outcome would be same as in case four (4).

\section{CONCLUSION}

A smart home surveillance was developed in this work. It consisted of a motion detection system using a PIR sensor and a USB webcam, a Radio Frequency Identification (RFID) based authentication system, a web application control panel, an alert system via phone call and email. This was achieved by the using raspberry pi as the main controller to which a USB camera, USB modem, PIR sensor, an RFID reader, an LED and a buzzer were connected. The various test scenarios (cases) showed the system to work satisfactorily and can be used as a convenient and cost-effective alternative security surveillance system.

\section{ACKNOWLEDGMENTS}

We are grateful to the Department of Electrical Electronics and Computer Engineering for their support in the development of this project. 


\section{REFERENCES}

[1] Mesnik, B. (2016).The History of Video Surveillance. Retrieved from https://kintronics.com/the-history-ofvideo-surveillance

[2] Nalini M., Kiran G.V (2017). Automatic Surveillance System Using Raspberry Pi And Arduino, International Journal of Engineering Sciences \& Research Technology, 6(5), 635-640.

[3] Sheshai.S.S (2016), Raspberry PI Based Security System, University Of Nairobi, Kenya.

[4] Ovseník, L., Kolesárová A., Turán J. (2010). Video Surveillance Systems, Acta Electrotechnica et Informatica, 10 (4), 46-53.

[5] Nosiri O.C., Akwiwu-Uzoma C.C., Nmaju U.A., Elumeziem C.H.(2018).Motion Detector Security System for Indoor Geolocation. International Journal of Engineering and Applied Sciences (IJEAS), 5(11), 2430 .

[6] Lee H.K., Chuah C.W (2018).Smart Indoor Home Surveillance Monitoring System Using Raspberry, International Journal on Informatics Visualization, 2(4), 299-308.

[7] Nasimuzzaman C., Shiblee, N., Sarker S., (2013), Access Control of Door and Home Security by Raspberry Pi through Internet. International Journal of Scientific and Engineering Research, 4(11), 550-558.

[8] Angela A., Gidveer G. R (2016). Live Streaming Motion Detection Camera Security System with Email Notification using Raspberry $\mathrm{Pi}$, IOSR Journal of Electronics and Communication Engineering (IOSRJECE), 142-147. 